\title{
Socio-Economic Factors, Food Habits and Phosphorus Levels in Patients on Hemodialysis
}

\author{
Domenico Santoro ${ }^{1, *}$; Maria Teresa Ingegnieri ${ }^{1}$; Giuseppe Vita ${ }^{1}$; Silvia Lucisano ${ }^{1}$; Carmelo \\ Zuppardo $^{1}$; Valeria Canale ${ }^{1}$; Vincenzo Savica ${ }^{1}$; Michele Buemi ${ }^{1}$ \\ ${ }^{1}$ Department of Clinical and Experimental Medicine, AOU G MArtino University of Messina, Messina, Italy \\ ${ }^{*}$ Corresponding author:Domenico Santoro, Department of Clinical and Experimental Medicine, AOU G MArtinoUniversity of Messina,P. O. Box: 98100, Messina, Italy.Tel/Fax:+39-0902212331, \\ E-mail: santisi@hotmail.com
}

Received: January 19, 2015; Revised: February 7, 2015; Accepted: February 14, 2015

\begin{abstract}
Background: Hyperphosphoremia is one of the most important risk factors for morbidity and mortality for chronic kidney disease (CKD) patients, and also, for the general population. Excessive dietary intake of phosphate $(\mathrm{P})$ is one of the key factors. In particular, $\mathrm{P}$ in its inorganic form, which is contained in food additives, is more readily absorbed. Unfortunately, these food additives are mostly present in convenience so called "fast foods" (pre-cooked), soft drinks, which represent the typical food consumed by our hemodialysis (HD) population, composed by elderly people, mostly low-socio economic class, who often live alone.

Objectives:We performed an observational retrospective multicenter study to find any association between social, cultural and economic situation, as well as food habits, and P levels in a cohort of patients on HD. Secondarily; we also examined the association between the fast food consumption and increased $\mathrm{P}$ levels, as well as patient compliance for $\mathrm{P}$ binding products.

Patients and Methods: To explore the association between socio-economic factors and serum P levels, we enrolled 100 patients on periodic HD treatment from three different units. Information on social, cultural, economic, diet habits, therapy for hyperphosphoremia and hematological and clinical parameters had been collected through specific questionnaires, administered by a physician.

Results: Results showed serum P level was reduced in patients who live alone compared to patients in family $(\mathrm{P}=0.04)$, in self-sufficient $(\mathrm{P}$ $=0.05$ ) and in patients belonging to middle-upper class, versus low-class $(\mathrm{P}=0.003)$. Fast foods intake correlates with increase in $\mathrm{P}$ serum levels $(\mathrm{P}=0.002)$, whilst the same correlation was not found for cheese intake. Our data show that socio-economic status and food habits are useful predictors of P serum levels.

Conclusions: In conclusion, dietary counseling of patients on HD is mandatory. Interventions that consider the socio-economic situation allow delivering important messages on foods with the least amount of P and adequate protein content, and they may be a successful strategy in targeting patients at a higher risk of hyperphosphoremia.
\end{abstract}

Keywords: Phosphates; Kidney Failure; Chronic; Socioeconomic Factors; Fast Foods

\section{Background}

Impaired phosphate (P) homeostasis is a widespread condition that involves patients with different degrees of renal failure, from stage III chronic kidney disease (CKD), to end stage renal disease (ESRD). The progressive deterioration of kidney function in CKD leads to retention of many substances, including phosphorus (P), that are normally excreted by the kidney. As a result, these patients tend to develop hyperphosphatemia, especially in settings of high P intake. Furthermore, this metabolic alteration is closely associated with increased morbidity and mortality in uremic patients (1-3). Indeed, an association has been shown between high serum P levels and increased death risk in patients with ESRD on dialysis $(2,4)$ and in individuals with lower stages of CKD (5). Converse- ly, a recent meta-analysis was unable to demonstrate any strong or consistent association between death and serum levels of parathyroid hormone or calcium, in individuals with CKD, while there was an association between death and higher serum levels of $P$, that was independent from the stage of kidney disease (6). Hyperphosphatemia also seems to be associated with a faster progression rate of CKD (7). Moreover, emerging data indicate that in nonCKD patients, high normal serum $P$ levels increase the risk for coronary artery calcification and mortality (8-10). Excessive dietary intake of $\mathrm{P}$ is one of the key factors. Since $P$ exists in virtually all living organisms, we can find it in the majority of foods. There are several sources of dietary P, such as different types of organic phospho-

Copyright ( ) 2015, Nephrology and Urology Research Center. This is an open-access article distributed under the terms of the Creative Commons Attribution-NonCommercial 4.0 International License (http://creativecommons.org/licenses/by-nc/4.0/) which permits copy and redistribute the material just in noncommercial usages, provided the original work is properly cited. 
rus in protein-rich foods, including animal foods, dairy products, meat, and fish, as well as plant foods, like legumes, nuts, and chocolates, along with inorganic $P$, in the form of food additives (11). Phosphorus-containing additives are increasingly being added to processed and fast foods, particularly meats, cheeses, baked goods, and beverages. These P salts are used to preserve moisture or color, to emulsify ingredients and enhance flavor, and to stabilize foods $(12,13)$. Phosphorus-containing additives are the most rapidly growing source of dietary P over the last decades and may contribute to one-third of the overall P intake in the general population (14). Unfortunately, convenience fast food and soft drinks are the typical food consumed by our hemodialysis (HD) population, composed of the elderly people, mostly low-socio economic class, who often live alone.

\section{Objectives}

We performed an observational retrospective multicenter study to find any association between social, cultural and economic situation, as well as food habits and $\mathrm{P}$ levels in a cohort of patients on HD. Secondly; we also examined the association between the fast food consumption and increased P levels, as well as patient compliance for $\mathrm{P}$ binding products.

\section{Patients and Methods}

\subsection{Study Sample}

Totally, 100 patients with ESRD on HD treatment were enrolled for this study, from three different centers in the province of Messina: unit of nephrology and dialysis, university of Messina (35 patients); unit of nephrology, AO Papardo (33 patients); Omega-unit of dialysis (32 patients). All participants were aged $>18$ years and had been performing HD for at least 12 months. We excluded incident HD patients, because of the changes in nutritional behavior and food intake during the first months of dialysis. Patients unable to collaborate or with unique nutritional requirements (nursing home resident, AIDS, active malignancy, terminal illness, inflammatory disease) were also excluded from the study.

There were 40 women, age $68.68 \pm 11.27$ years, duration of dialysis 51.77 months. The body mass index (BMI) was $21.5 \pm$ 4.6. Study coordinators approached all patients during dialysis treatment, told them about the goals of the study and obtained written informed consent.

The causes of renal failure were diabetes $(\mathrm{n}=44)$, nephroangiosclerosis $(n=21)$, chronic glomerulonephritis $(n=15)$, polycystic kidney $(n=6)$ and other causes $(\mathrm{n}=11)$.

The local ethics committee approved the protocol. The study was conducted in accordance with the guidelines of the Helsinki Declaration on ethical principles for medical research involving humans.

\subsection{Questionnaires}

Patients' data were obtained through questionnaires that were designed for the study purpose. The questionnaire consisted of items corresponding to socio-economic status, level of education, dietary habits of the patients, namely skipping meals, where meals were consumed, if they eat alone, what was their usual diet, and, finally, if they made use of fast foods, as well as the quantity of cheeses.

Through the questionnaire regarding fast-food (precooking food), we obtained important information on the dietary habits of the patients, of which we have considered especially the frequency with which they take pre-cooked food.

Patients were divided into four groups:1) patients who did not eat pre-cooked food; 2 ) patients who were taking them rarely (one-three times a week); 3) patients who received pre-cooked meals often (four-six times a week); 4) patients who were taking only precooked foods (seven-10 times a week).

Questionnaires were filled with the help of a study coordinator. The patient and the coordinator were alone, to avoid any possibility that the presence of other people could lead to different responses from the reality. The tests were easy to understand, with short and concise questions. All questions were developed with the help of a panel of renal dietitians, HD patients and nephrologists and were pilot tested prior to use for this study.

Medical records and dietary habits of participants were pulled out, from unblended study coordinators to obtain personal data. Through the assessment of economic status, level of education and skills of individual patients, we divided the patients into three groups:1) upper-class, 2) middle-class, and 3) low-class.

\subsection{Parameters Studied}

Common biochemical parameters, including urea, creatinine, uric acid, serum lipids, total serum calcium, $\mathrm{P}$, calcium-phosphate product, serum iron, electrolytes, albumin, hemoglobin, total alkaline phosphatases, calcitriol, proteinuria, fibrinogen, homocysteine, $\beta 2$ microglobulin and high sensitivity C-reactive protein (were measured at baseline, in all patients and controls, according to standard methods in the routine clinical laboratory. Intact parathyroid hormone was also measured by immunoradiometric assay, using the Elecsys 2010 autoanalyzer system (Roche Diagnostics, Basel, Switzerland).

\subsection{Statistical Analysis}

Statistical analyses were performed with NCSS for Windows (version 4.0), the MedCalc (version 8.0) software, and the GraphPad Prism (version 5.0) package. Data were presented as Mean \pm SD for normally distributed values (at Kolmogorov-Smirnov test) and median [IQ range] for non-normally distributed values. Differences between groups were established by unpaired t-test for normally 
distributed values and by Kruskal-Wallis analysis, followed by Dunn's test for nonparametric values. Spearman's correlation coefficient was searched to examine the relation between variables. Before testing correlations, all non-normally distributed values were log-transformed to better approximate normal distributions. Stepwise multiple regression analyses were performed in order to assess independent relationships. All results were considered significant if P was less than 0.05.

\section{Results}

\subsection{Characteristics of Hemodialysis Patients}

The main characteristics of the study cohort are summarized in Table 1. The mean age of patients was $68.68 \pm 11.27$ years. Mean duration of dialysis was $51.77 \pm 22.1$ months. The level of education of the patients were middle-low: $4 \%$ were illiterate, $36 \%$ had a license to primary school, $22 \%$ had a diploma of first degree of secondary school, 26\% had a diploma of secondary degree of secondary school, and, finally, only $12 \%$ graduated an university.

A proportion of $65 \%$ of the patients were married/ cohabiting, whereas $35 \%$ of patients lived alone. In particular, $19 \%$ were widow/widower, $12 \%$ were single/never married, and $14 \%$ were separated/ divorced. Of the examined patients, $80 \%$ were self-sufficient, while $20 \%$ was in a state of dependency.

\subsection{Phosphorus and Socio-Economic Conditions}

Serum p levels were higher in patients who lived alone compared to patients in family $(\mathrm{P}=0.04)$ and in self-sufficient $(\mathrm{P}=0.05)$ (Figure 1). Phosphorus levels were also higher in patients belonging to low-class of socio-economic status. A reduction in phosphorus levels has been detected in patients belonging to middle-class $(\mathrm{P}=0.003)$ (Figure 2).

\subsection{Consumption of Fast Food (Pre-Cooked) Food}

Fifty percent of patients were used to have precooked foods from four to six times a week. Regarding the socioeconomic status, patients belonging to the low-class made greater use of foods containing additives and had high serum P levels $(5.49 \pm 1.32 \mathrm{mg} / \mathrm{dL})$ compared with patients in the upper-class $(4.48 \pm 0.52 \mathrm{mg} / \mathrm{dL})(\mathrm{P}=0.003)$.

The assumption that precooked foods significantly increase $P$ levels $(P=0.002)$ was verified, whereas the intake of cheese was not significantly associated with levels of phosphorus ( $\mathrm{P}=0.09$ ) (Figure 3). The pre-cooked meals and the socio-economic status appear predictive of changes in the levels of $\mathrm{P}$.

\subsection{Phosphorus and Drugs}

Phosphorus binding drugs were used by the $84 \%$ of examined patients, and of these, $26 \%$ were taking more than one drug. The drug most used was sevelamer (64\%), followed by calcium-carbonate (18\%), aluminum-hydroxide (13\%) and lanthanum-carbonate (5\%).
Of patients who were taking only one drug, 83\% used sevelamer, $9 \%$ calcium-carbonate, $5 \%$ lanthanum-carbonate and 3\% aluminum-hydroxide.

The most frequent cause of referred limitation in drug assumption was the low palatability and the high number of pills. Indeed, only $44 \%$ were taking medication correctly, whilst $55 \%$ of patients reduced the dosage of prescribed medications and $1 \%$ increased the dosage.

\begin{tabular}{|c|c|}
\hline Parameter & $\begin{array}{l}\text { HD Patients } \\
\quad(\mathbf{n}=\mathbf{1 0 0})\end{array}$ \\
\hline \multicolumn{2}{|l|}{ Gender } \\
\hline Male & 40 \\
\hline Female & 60 \\
\hline Age, $y^{b}$ & $68.68 \pm 11.27$ \\
\hline Dialysis age, mo ${ }^{b}$ & $51.77 \pm 22.1$ \\
\hline \multicolumn{2}{|l|}{ Educational attainment $^{c}$} \\
\hline None (illiterate) & 4 \\
\hline Primary school & 36 \\
\hline First degree of secondary school & 22 \\
\hline Secondary degree of secondary school & 26 \\
\hline Graduated at university & 12 \\
\hline \multicolumn{2}{|l|}{ Marital status ${ }^{c}$} \\
\hline Married/cohabiting & 65 \\
\hline Widow/widower & 19 \\
\hline Single/never married & 12 \\
\hline Separated/divorced & 14 \\
\hline \multicolumn{2}{|l|}{ Family conditions $c$} \\
\hline Living in charity & 3 \\
\hline Living alone & 11 \\
\hline Living in family & 82 \\
\hline Living with a caregiver & 4 \\
\hline Low-class & 40 \\
\hline \multicolumn{2}{|l|}{ Socio-economic status ${ }^{c}$} \\
\hline Upper-class & 10 \\
\hline Middle-class & 50 \\
\hline \multicolumn{2}{|l|}{ Relational autonomy ${ }^{c}$} \\
\hline Self-sufficient & 80 \\
\hline Dependent & 20 \\
\hline \multicolumn{2}{|l|}{ Consumption of pre-cooked food ${ }^{\mathrm{C}}$} \\
\hline Often ( 4 - 6 times a week) & 50 \\
\hline Rarely (1 - 3 times a week) & 37 \\
\hline Always (7 -10 times a week) & 6 \\
\hline Never & 7 \\
\hline \multicolumn{2}{|l|}{ Phosphate binder's use c } \\
\hline Sevelamer & 64 \\
\hline Calcium carbonate & 18 \\
\hline Aluminum hydroxide & 13 \\
\hline Lanthanum carbonate & 5 \\
\hline
\end{tabular}



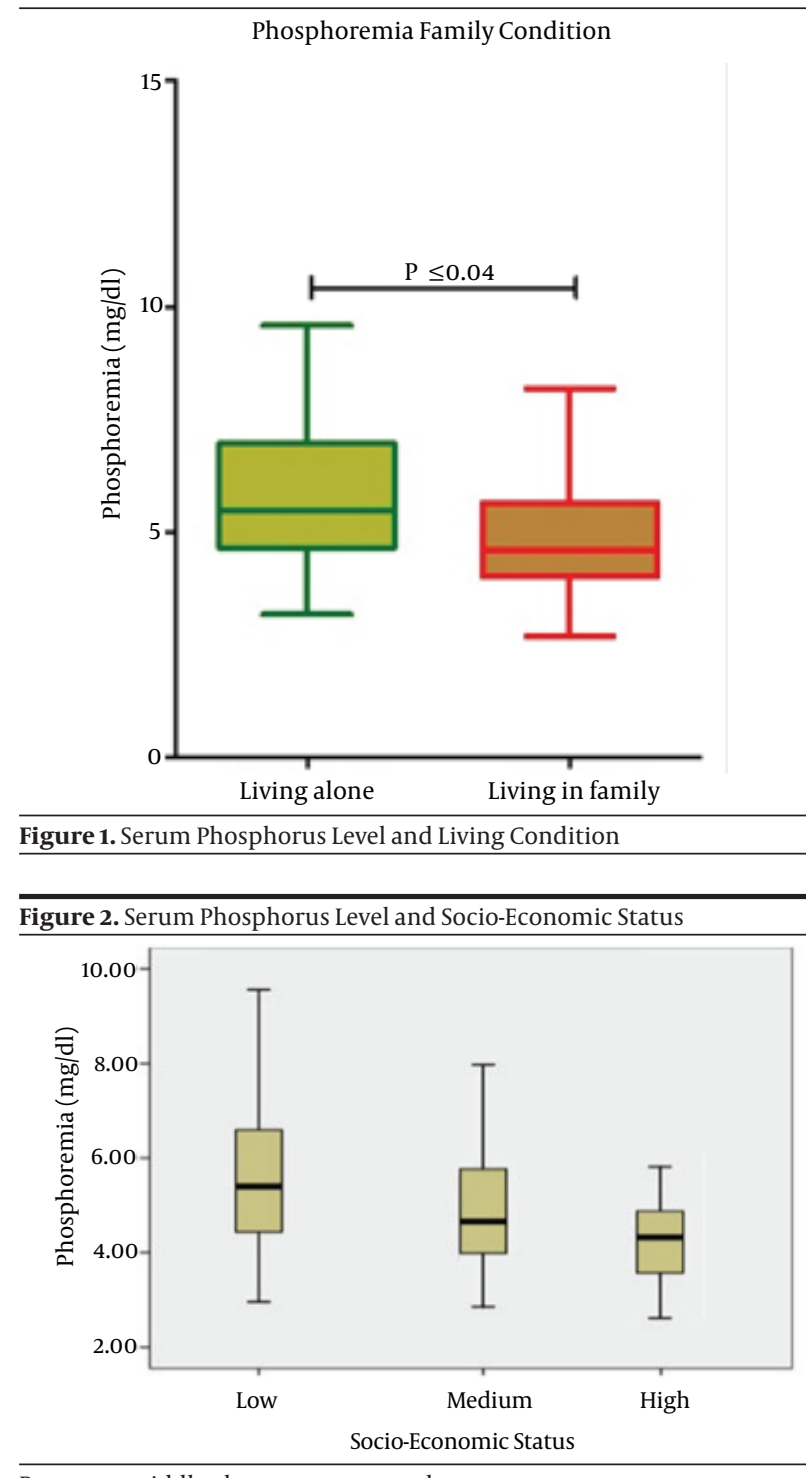

$\mathrm{P}=0.003$, middle-class versus upper-class.

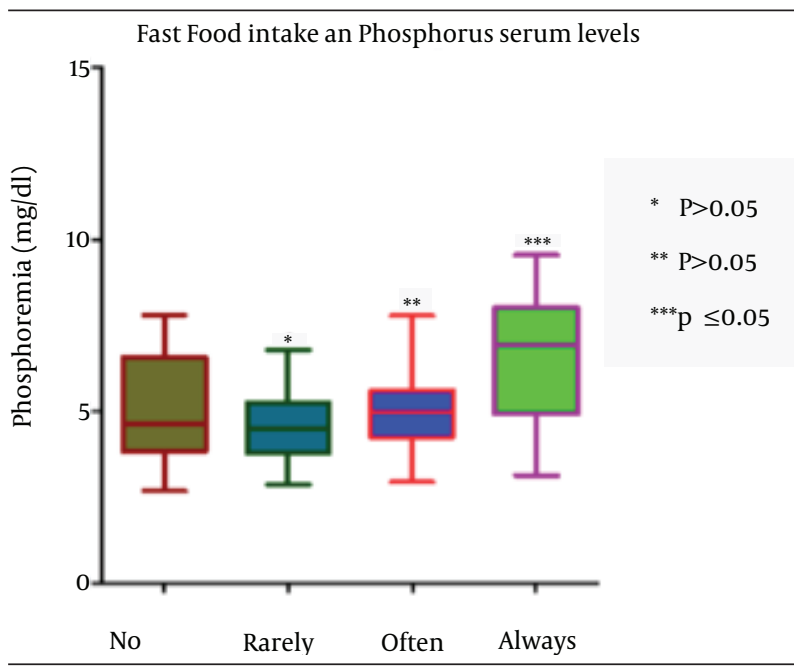

Figure 3. Serum Phosphorus Level and Frequency of Fast Foods Intake

\section{Discussion}

Dietary intake of $\mathrm{P}$ and the serum $\mathrm{P}$ concentration are important spects in patients with renal disease. During the course of CKD, many substances, which are normally excreted by the kidney, are retained in the body. Serum $\mathrm{P}$ concentration is usually maintained within the normal range of 2.5 to $4.5 \mathrm{mg} / \mathrm{dL}$, by a variety of compensatory mechanisms, until renal disease has progressed to approximately stage 4 - 5 CKD (15). An effective mechanism is the reduction in renal tubular absorption of phosphate (PO4), i.e. increased fractional excretion of P regulated by parathyroid hormone (PTH) and by the phosphatonin fibroblast growth factor $23(16,17)$. In advanced stages of CKD, these mechanisms become inadequate to remove the P load, causing hyperphosphatemia $(18,19)$. The Kidney Disease Outcomes Quality Initiative (Clinical Practice Guidelines for Bone Metabolism and Disease recommend that serum P levels should be maintained between 2.7 and $4.6 \mathrm{mg} / \mathrm{dL}$ in patients with CKD stages 3 and 4, and between 3.5 and $5.5 \mathrm{mg} / \mathrm{dL}$ in dialysis patients (20).

Different therapeutic approaches are today available in clinical practice, to treat P balance disorders, such as dietary restrictions, adequate dialysis schedule and oral phosphate binders administration (21).

Despite these approaches, normalization of serum Plevels is often difficult and frequently not obtained. Recent data suggest that less than $50 \%$ of patients meet target levels for serum $\mathrm{P}$ (22). Excessive dietary intake of $\mathrm{P}$ is one of the key factors. Our study showed that the majority of HD patients (50\%) made use of pre-cooked foods from four to six times a week.

The PO4 additives can dramatically increase the amount of $\mathrm{P}$ consumed in the daily diet, especially because $\mathrm{P}$ is more easily absorbed in its inorganic form. In contrast, plant food, seeds and legumes that are rich in P, are usually associated with lower intestinal $\mathrm{P}$ absorption because of phytates in these foods. Moreover, the P load from the food additives in fast food, soft drinks and processed cheese and snacks is disproportionately high, in relation to their dietary P content, compared to natural P sources from animal-based (excluding dairy products) and plantderived foods.

In these products, information on the P content and the type of preparation of food is often unavailable or misleading (11). Therefore, the increased use of food additives rich in $\mathrm{P}$, together with the growing popularity of ready meals and attendance of fast food restaurants, has greatly increased the amount of P consumed by both the general population and patients with CKD (23).

In a recent randomized controlled trial, Sullivan et al. (16) have shown that the inorganic P in processed foods contributed significantly to the P load of dialysis patients and educating patients with ESRD to avoid P containing food additives, leads to improvements in hyperphosphatemia.

Several studies have highlighted the contribution of socio-economic inequalities in health and mortality (24- 
26). Lower socio-economic status was independently associated with higher serum phosphate concentrations and higher likelihood of hyperphosphatemia among a diverse cohort of individuals participating in the CRIC Study (27).

Gutierrez et al. (27) shown that increasing poverty was independently associated with higher serum P levels and greater likelihood of hyperphosphatemia in a cohort of over 14,000 adults with largely preserved kidney function. Compared with participants in the highest quartile (income more than 300\% of the federal poverty level), participants in the lowest quartile (income less than the federal poverty level) had more than twice the odds of hyperphosphatemia ( $\geq 4.4 \mathrm{mg} / \mathrm{dL})(27)$.

In another study, Gutierrez et al. (28) performed a cross-sectional analysis of race, socio-economic status, and serum P among 2879 participants in the Chronic Renal Insufficiency Cohort. Low socioeconomic status was associated with higher serum P concentrations, irrespective of race (28).

These data suggest that a low socio-economic status is a novel risk factor for increased serum $P$ concentrations in CKD. We studied patients on HD and we have shown that elderly subjects, in middle-class regarding socio-economic and cultural status, represent the majority of this population. Patients living in lower socio-economic conditions had higher levels of $\mathrm{P}(\mathrm{P}=0.003)$. In this group, patients used to consume foods with highly absorbable and indeterminate $\mathrm{P}$ additives, explaining their higher likelihood of hyperphosphoremia. Indeed, the intake of pre-cooked food significantly increased serum $\mathrm{P}$ level $(\mathrm{P}=0.002)$.

These results confirm and strengthen evidences emerging from previous studies $(16,29)$. We also evaluated drug compliance of HD patients and observed that 55\% of them individually reduce the dosage of the medications prescribed as P binders. The most frequent limitation in taking these drugs is low palatability and the high frequency of administration. These drugs are associated with gastrointestinal intolerance side effects (nausea, vomiting, abdominal pain, bloating, diarrhea, and constipation) that represent the most common reason for drugs discontinuation in CKD patients (21).

The poor compliance, combined with the high consumption of convenience food, makes very difficult to control P levels in these patients. Whereas, as already mentioned, increased serum $\mathrm{P}$ is associated with cardiovascular disease, kidney disease progression, and death (1-10). Keeping the values of $P$ in the normal range becomes a fundamental objective in patients with CKD. The increase in $\mathrm{P}$, through promoting vascular calcification, endothelial dysfunction, and renal injury, suggests a causal link between elevated serum $P$ and adverse health outcomes (30-33).

A thorough nutritional assessment and an adequate diet are crucial in HD patients. It would be useful to sensitize patients to follow a diet with a low load of P. A mixed composition of food from plant and food from animal origin should be encouraged, while the intake of processed foods should be limited. More detailed information of the P content of foods, described by manufacturers, can lead to better control of phosphorus intake with the diet. Finally, considering that patients show reduced compliance, in respect of drugs acting on the calcium-phosphorus balance, diet therapy plays an even more important role in the management of patients with ESRD.

In conclusion, we observed that the food containing hidden $\mathrm{P}$ is preferred for people who, besides having a low socio-economic status, also live alone, and, for this reason, consume unhealthy food. This is one of the firsts studies that correlate poverty and the condition of living alone (very often associated with depression) with serum P levels. Because of the strong association of these conditions with the diet quality, we wanted to stress the interventions that consider the population with low socioeconomic situation, to deliver important messages on foods with the least amount of $\mathrm{P}$ and adequate protein content, and this may be a successful strategy in targeting patients at a higher risk of hyperphosphoremia.

\section{Authors' Contributions}

Study concept and design: Domenico Santoro. Acquisition of data: Maria Teresa Ingegnieri. Analysis and interpretation of data: Domenico Santoro, Maria Teresa Ingegnieri and Giuseppe Vita. Drafting of the manuscript: Domenico Santoro, Maria Teresa Ingegnieri, and Silvia Lucisano. Critical revision of the manuscript for important intellectual content: Michele Buemi and Vincenzo Savica. Statistical analysis: Giuseppe Vita. Administrative, technical, and material support: all of the authors. Study supervision: Carmelo Zuppardo, and Valeria Canale.

\section{References}

1. Kestenbaum B, Sampson JN, Rudser KD, Patterson DJ, Seliger SL, Young B, et al. Serum phosphate levels and mortality risk among people with chronic kidney disease. J Am Soc Nephrol. 2005;16(2):520-8.

2. Block GA, Klassen PS, Lazarus JM, Ofsthun N, Lowrie EG, Chertow GM. Mineral metabolism, mortality, and morbidity in maintenance hemodialysis. J Am Soc Nephrol. 2004;15(8):2208-18.

3. Raggi P, Kleerekoper M. Contribution of bone and mineral abnormalities to cardiovascular disease in patients with chronic kidney disease. Clin J Am Soc Nephrol. 200 8;3(3):836-43.

4. Kalantar-Zadeh K, Kuwae N, Regidor DL, Kovesdy CP, Kilpatrick $\mathrm{RD}$, Shinaberger CS, et al. Survival predictability of time-varying indicators of bone disease in maintenance hemodialysis patients. Kidney Int. 2006;70(4):771-80.

5. Dhingra R, Sullivan LM, Fox CS, Wang TJ, D'Agostino RS, Gaziano JM, et al. Relations of serum phosphorus and calcium levels to the incidence of cardiovascular disease in the community. Arch Intern Med. 2007;167(9):879-85.

6. Palmer SC, Hayen A, Macaskill P, Pellegrini F, Craig JC, Elder GJ, et al. Serum levels of phosphorus, parathyroid hormone, and calcium and risks of death and cardiovascular disease in individuals with chronic kidney disease: a systematic review and metaanalysis. JAMA. 2011;305(11):1119-27.

7. Schwarz S, Trivedi BK, Kalantar-Zadeh K, Kovesdy CP. Association of disorders in mineral metabolism with progression of chronic kidney disease. Clin J Am Soc Nephrol. 2006;1(4):825-31.

8. Tonelli M, Sacks F, Pfeffer M, Gao Z, Curhan G, Cholesterol., et al. Relation between serum phosphate level and cardiovas- 
cular event rate in people with coronary disease. Circulation. 2005;112(17):2627-33.

9. Adeney KL, Siscovick DS, Ix JH, Seliger SL, Shlipak MG, Jenny NS, et al. Association of serum phosphate with vascular and valvular calcification in moderate CKD. JAm Soc Nephrol. 2009;20(2):381-7.

10. Foley RN, Collins AJ, Herzog CA, Ishani A, Kalra PA. Serum phosphorus levels associate with coronary atherosclerosis in young adults. J Am Soc Nephrol. 2009;20(2):397-404.

11. Noori N, Sims JJ, Kopple JD, Shah A, Colman S, Shinaberger CS, et al Organic and inorganic dietary phosphorus and its management in chronic kidney disease. Iran J Kidney Dis. 2010;4(2):89-100.

12. Uribarri J, Calvo MS. Hidden sources of phosphorus in the typical American diet: does it matter in nephrology? Semin Dial. 2003;16(3):186-8.

13. Murphy-Gutekunst L. Hidden phosphorus in popular beverages. Nephrol Nurs J. 2005;32(4):443-5.

14. Coates PM, Blackman MR, Cragg GM, Levine M, Moss J, White JD. Encyclopedia of Dietary Supplements.New York, NY: Marcel Dekker; 2005.

15. Ritz E, Hahn K, Ketteler M, Kuhlmann MK, Mann J. Phosphate additives in food-a health risk. Dtsch Arztebl Int. 2012;109(4):49-55.

16. Sullivan C, Sayre SS, Leon JB, Machekano R, Love TE, Porter D, et al. Effect of food additives on hyperphosphatemia among patients with end-stage renal disease: a randomized controlled trial. JAMA. 2009;301(6):629-35.

17. Hallan SI, Coresh J, Astor BC, Asberg A, Powe NR, Romundstad $\mathrm{S}$, et al. International comparison of the relationship of chronic kidney disease prevalence and ESRD risk. J Am Soc Nephrol. 2006;17(8):2275-84.

18. Kovesdy CP, Kalantar-Zadeh K. Bone and mineral disorders in pre-dialysis CKD. Int Urol Nephrol. 2008;40(2):427-40.

19. Isakova T, Gutierrez OM, Wolf M. A blueprint for randomized trials targeting phosphorus metabolism in chronic kidney disease. Kidney Int. 2009;76(7):705-16.

20. National Kidney F. K/DOQI clinical practice guidelines for bone metabolism and disease in chronic kidney disease. Am J Kidney Dis. 2003;42(4 Suppl 3):S1-201.

21. Tonelli M, Pannu N, Manns B. Oral phosphate binders in patients with kidney failure. N EnglJ Med. 2010;362(14):1312-24.

22. Young EW, Akiba T, Albert JM, McCarthy JT, Kerr PG, Mendelssohn DC, et al. Magnitude and impact of abnormal minera metabolism in hemodialysis patients in the Dialysis Outcomes and Practice Patterns Study (DOPPS). Am J Kidney Dis. 2004;44(5 Suppl 2):34-8.

23. Kalantar-Zadeh K, Gutekunst L, Mehrotra R, Kovesdy CP, Bross $\mathrm{R}$, Shinaberger CS, et al. Understanding sources of dietary phosphorus in the treatment of patients with chronic kidney disease. Clin J Am Soc Nephrol. 2010;5(3):519-30.

24. Dow WH, Rehkopf DH. Socioeconomic gradients in health in international and historical context. Ann N Y Acad Sci. 2010;1186:24-36.

25. Goldman D, Smith JP. The increasing value of education to health. Soc Sci Med. 2011;72(10):1728-37.

26. Adler NE, Stewart J. Health disparities across the lifespan: mean ing, methods, and mechanisms. Ann N Y Acad Sci. 2010;1186:5-23.

27. Gutierrez OM, Isakova T, Enfield G, Wolf M. Impact of poverty on serum phosphate concentrations in the Third National Health and Nutrition Examination Survey.J Ren Nutr. 2011;21(2):140-8.

28. Gutierrez OM, Anderson C, Isakova T, Scialla J, Negrea L, An derson AH, et al. Low socioeconomic status associates with higher serum phosphate irrespective of race. J Am Soc Nephrol. 2010;21(11):1953-60.

29. Bell RR, Draper HH, Tzeng DY, Shin HK, Schmidt GR. Physiological responses of human adults to foods containing phosphate additives. J Nutr. 1977;107(1):42-50.

30. Giachelli CM, Jono S, Shioi A, Nishizawa Y, Mori K, Morii H. Vascular calcification and inorganic phosphate. Am J Kidney Dis. 2001;38(4 Suppl 1):S34-7.

31. Ibels LS, Alfrey AC, Haut L, Huffer WE. Preservation of function in experimental renal disease by dietary restriction of phosphate. N EnglJ Med. 1978;298(3):122-6.

32. Mathew S, Tustison KS, Sugatani T, Chaudhary LR, Rifas L, Hruska KA. The mechanism of phosphorus as a cardiovascular risk factor in CKD. J Am Soc Nephrol. 2008;19(6):1092-105.

33. Shuto E, Taketani Y, Tanaka R, Harada N, Isshiki M, Sato M, et al Dietary phosphorus acutely impairs endothelial function. $J \mathrm{Am}$ Soc Nephrol. 2009;20(7):1504-12. 